\title{
Interactive comment on "Exploring sources of biogenic secondary organic aerosol compounds using chemical analysis and the FLEXPART model" by Johan Martinsson et al.
}

Johan Martinsson et al.

johan.martinsson@nuclear.lu.se

Received and published: 28 June 2017

The interactive comments were uploaded in the form of a supplement:

Please also note the supplement to this comment:

https://www.atmos-chem-phys-discuss.net/acp-2017-90/acp-2017-90-AC3-

supplement.pdf 